\title{
PREDICTING FOODSTUFF FROM JAW DYNAMICS DURING MASTICATORY CRUSHING IN MAN
}

\author{
J.-S. WANG and C. S. STOHLER* \\ Stomatognathic Physiology Laboratory, School of Dentistry, The University of Michigan,
} Ann Arbor, MI 48109-1078, U.S.A.

(Accepted 22 August 1990)

\begin{abstract}
Summary - In previous in vitro experiments using an Instron instrument, each test food was found to have characteristic textural properties. In vivo experiments were now made (1) to determine the degree to which variations in the vertical jaw movements during the crushing phase of mastication can be explained by the inherent properties of the foodstuff being chewed, and (2) to establish the degree to which the foodstuff being chewed can be identified by certain features of the jaw dynamics. Five adults were used for chewing tasks with standardized picces of beef, carrot or peanut. Each subject made two trials with cach foodstuff. The movement of the lower incisal point was monitored; features of movement associated with jaw closing in the first chewing cycle were considered. Five of these features were not suitable to categorize the various test foods. Each of the remaining 4, however, was able to distinguish either one food from the 2 others ( 2 cases), or one from another ( 2 cases). Pattern recognition techniques based upon principal component analysis could differentiate jaw closing patterns associated with chewing beef from those involving peanut or carrot. The extent to which peanut could be distinguished from carrot was not as predictable as the categorization of peanut or carrot versus beef. Cross-correlation of in vitro force-time breakage characteristics and the jaw movement data showed that on average $52 \%$ of the variation in the vertical jaw movement during crushing of food could be explained by the inherent properties of the food. Because the masticatory apparatus acts as a low-pass filter, the high-frequency components of food breakage characteristics found in vitro were attenuated in vivo. It appears that the inherent filter properties of the masticatory apparatus limit the range of sensory and motor function of the jaw.
\end{abstract}

Key words: mastication, muscle physiology, mandibular movement.

\section{INTRODUCTION}

Little is known about force control during voluntary biting and chewing. Monkeys, trained to produce a steady bite force, lost this ability after bilateral ablation of the precentral face area; the force-holding task could be relearned, but voluntary control was compromised (Luschei and Goodwin, 1975; Luschei and Goldberg, 1981). These lesions did not prevent animals from eating after surgery, but the act of chewing appeared to be impaired; one animal required feeding with an intragastric tube for a few days (Luschei and Goldberg, 1981). In monkeys, Hoffman and Luschei (1980) identified neurones in the face area of the precentral cortex that consistently increased their discharge rate before or shortly after the onset of isometric bite force. Hyperactivity of cortical neurones has also been found during the first few strokes after ingestion of food in the rabbit; this response disappears later in the chewing sequence (Enomoto et al., 1987). Based on this evidence, it is reasonable to conclude that the face area of the precentral cortex is not essential for controlled biting tasks. In intact subjects, however, its contribution during voluntary biting and in the early part of the chewing sequence should be regarded as significant.

*To whom correspondence should be addressed.
Speed of contraction is a variable of particular interest in the context of chewing. Differences between the forces at which motor neurones are recruited during slow ramp and ballistic contractions are small with the masseter when compared to the limb system (Desmedt and Godaux, 1978). In order to obtain insight into the requirement for force control during mastication, knowledge of the mechanics of food breakage is essential.

It is generally assumed that the mechanical and geometrical properties of food shape the masticatory behaviour in terms of force generation and jaw movement (Ahlgren, 1966; Moller, 1966; Luschei and Goodwin, 1974; Bates, Stafford and Harrison, 1975; Hiiemae, 1978; Haraldson and Ingervall, 1979; Hylander and Johnson, 1989). However, it is not known to which degree these food properties influence jaw dynamics during crushing. In previous in vitro experiments, we demonstrated that each test food has particular breakage properties as reflected in characteristic details of the force-time curves (Wang and Stohler, 1990). We now aimed to determine (1) the extent to which variations in features of vertical jaw movements during the crushing phase of mastication can be explained by inherent properties of the foodstuff being chewed, and (2) the extent to which the foodstuff being chewed can be identified by the features of the jaw dynamics. 


\section{MATERIALS AND METHODS}

\section{Subjects $^{+}$}

Five adult volunteers, 2 female and 3 male, were selected as experimental subjects; mean age was $31 \mathrm{yr}$, ranging from 28 to $33 \mathrm{yr}$. All subjects had a complete or almost complete dentition with third molars as the only missing teeth in both arches. None had a history of facial pain and/or masticatory problems, or complained about symptoms associated with temporomandibular disorders at the time of the experiment.

\section{Experimental procedure}

Experiments were performed in a radio-frequency shielded room. Subjects were seated upright against a comfortably adjusted chair with back-rest. Three different foods of standardized size were provided: (1) carrot (10 mm cubes); (2) single peanut (dry roasted blanched peanut, $5 \mathrm{~mm}$ thickness on average; Food Club, Skokie, IL, U.S.A.); and (3) beefsteak without skin ( $8 \mathrm{~mm}$ thickness on average; Bridgford Foods Corp., Chicago, IL, U.S.A.). Subjects were asked to chew these standardized pieces of test food in their habitual manner. Food was presented in the order (1) carrot, (2) peanut and (3) beef. Gum chewing was requested between trials to ensure that all food residue were removed from the occlusal surfaces before the next recording. Movement of the incisal point was tracked by means of a Mandibular Kinesiograph (MKG-5 Research, Myotronics Inc., Seattle, WA, U.S.A.). Subjects were asked to keep the jaw closed before each trial so that full closure could be calibrated. Vertical jaw movement data were digitized on-line at a sampling rate of $500 \mathrm{~Hz}$ and stored directly on hard disk.

\section{Data analysis}

Data analysis focused on the vertical movement component of the food crushing phase of the first chewing cycle in the masticatory sequence. The first and closest point to full closure was considered as the end point of the crushing phase. Vertical jaw movement data were differentiated by interpolating a fourth-degree polynomial through 5 consecutive data points, and then computing its first and second derivatives, representing velocity and acceleration data (Stohler, Ashton-Miller and Carlson, 1988). Jaw movement dynamics were expressed by 9 parameters (Table 1). Tooth-food contact was given by the first peak in the velocity trace in the jaw closing phase, following which the velocity decreased due to food contact (Fig. 1).

\section{Statistical analysis}

(A) Analysis of variance: Using a repeated measures design, each movement parameter was tested by means of one-way analysis of variance. If found significant, a multiple comparison (paired $t$-test with Bonferroni's correction) was used to distinguish the difference between test foods. (B) Pattern recognition: Pattern recognition techniques based upon principal component analysis were applied to categorize the observations of the jaw movement dynamics in order to establish the degree to which the foodstuff could be identified on the basis of vertical jaw movement, velocity, and acceleration data. (C) Cross correlation: Cross-correlation analysis was used to explain the degree of variation of in vivo jaw dynamics, based upon in vitro force-time breakage characteristics established by Wang and Stohler (1990).

Analysis of variance and pattern recognition analysis was based upon the average of 2 trials of the defined jaw movement parameters of each of the 5 subjects. In the case of cross-correlation analysis, force-time curves of carrot, peanut, and beefstick, obtained by means of an Instron instrument at a cross-head speed of $5 \mathrm{~cm} / \mathrm{min}$ were digitized at a sampling frequency of $520 \mathrm{~Hz}$. An average force-time curve was computed from 8 in vitro trials of each test-food. By means of second-order polynomial regression, jaw movement data were sampled so that an identical number of data points was obtained as by sampling the in vitro force-time curve.

\section{RESULTS}

The vertical jaw movement trace during crushing of different foods had marked differences within each

Table 1. Vertical jaw movement parameters

\begin{tabular}{|c|c|}
\hline $\begin{array}{l}\text { Parameters of jaw } \\
\text { movement dynamics }\end{array}$ & Definitions/criteria \\
\hline $\begin{array}{l}\text { Count of velocity } \\
\text { minima (VMI) }\end{array}$ & $\begin{array}{l}\text { Number of velocity minima } \\
\text { (velocity decrease followed by an increase of }>3 \mathrm{~mm} / \mathrm{s} \text { ) }\end{array}$ \\
\hline $\begin{array}{l}\text { Count of velocity } \\
\text { maxima (VMA) }\end{array}$ & $\begin{array}{l}\text { Number of velocity maxima } \\
\text { (velocity increase followed by a decrease of }>10 \mathrm{~mm} / \mathrm{s} \text { ) }\end{array}$ \\
\hline $\begin{array}{l}\text { Maximum positive } \\
\text { acceleration (MPA) }\end{array}$ & In $\mathrm{mm} / \mathrm{s}^{2}$ \\
\hline $\begin{array}{l}\text { Maximum negative } \\
\text { acceleration (MNA) }\end{array}$ & In $\mathrm{mm} / \mathrm{s}^{2}$ \\
\hline $\begin{array}{l}\text { First breakage } \\
\text { acceleration (FBA) }\end{array}$ & In $\mathrm{mm} / \mathrm{s}^{2}$ \\
\hline $\begin{array}{l}\text { Final occlusal } \\
\text { clearance (FOC) }\end{array}$ & Vertical opening at the end of the 1 st crushing cycle in $\mathrm{mm}$ \\
\hline First deceleration (FD) & Deceleration at the initial tooth - food contact in $\mathrm{mm} / \mathrm{s}^{2}$ \\
\hline $\begin{array}{l}\text { Velocity at tooth-food } \\
\text { contact (VC) }\end{array}$ & Velocity at the initial tooth-food contact in $\mathrm{mm} / \mathrm{s}$ \\
\hline $\begin{array}{l}\text { Temporal location of the } \\
\text { lst breakage point (TLBP) }\end{array}$ & $\begin{array}{l}\text { Time needed from initial tooth-food contact to the first clear spike } \\
\text { in the velocity trace divided by the total time of the crushing phase }\end{array}$ \\
\hline
\end{tabular}


subject (Fig. 2). In all subjects and trials, the vertical jaw movement associated with chewing carrots showed a sudden, closing deflection. Surprisingly, a similar event was not observed with chewing peanuts.

The descriptive statistics of the jaw movement parameters are presented in Table 2. By means of one-way analysis of variance, only 5 of the 9 parameters were found to be statistically significant between foods. These were VMI (count of velocity minima), VMA (count of velocity maxima), MPA (maximum positive acceleration), FOC (final occlusal clearance) and FD (first deceleration). With the multiple comparison (Bonferroni's correction after paired $t$-test), only 4 parameters were able to distinguish either one test food from the 2 others, or one from another. Parameters such as MNA (maximum negative acceleration), FBA (first breakage acceleration), FD (first deceleration at tooth-food contact) and TLBP (temporal location of the first breakage point in the compression cycle) were not suitable for distinguishing the food being chewed. Results of the statistical analysis are given in Table 3.

By means of pattern recognition techniques, the crushing patterns of beef proved to be clearly different from those of peanut or carrot. The degree to which peanut could be distinguished from carrot was not as predictable as the categorization of peanut or carrot versus beef (Fig. 3).

The extent to which the jaw movement trace could be explained by the in vitro food breakage properties ranged from 35 to $69 \%$ (52\% on average) for all subjects, foods and trials. Because of a hard-disk failure, we were unable to recover some data. For this reason, we could not compute the cross-correlation coefficient of subject No. 5 for chewing beef. In the case of crushing peanut and depending on the subjects, $59-69 \%$ of the variation in the vertical
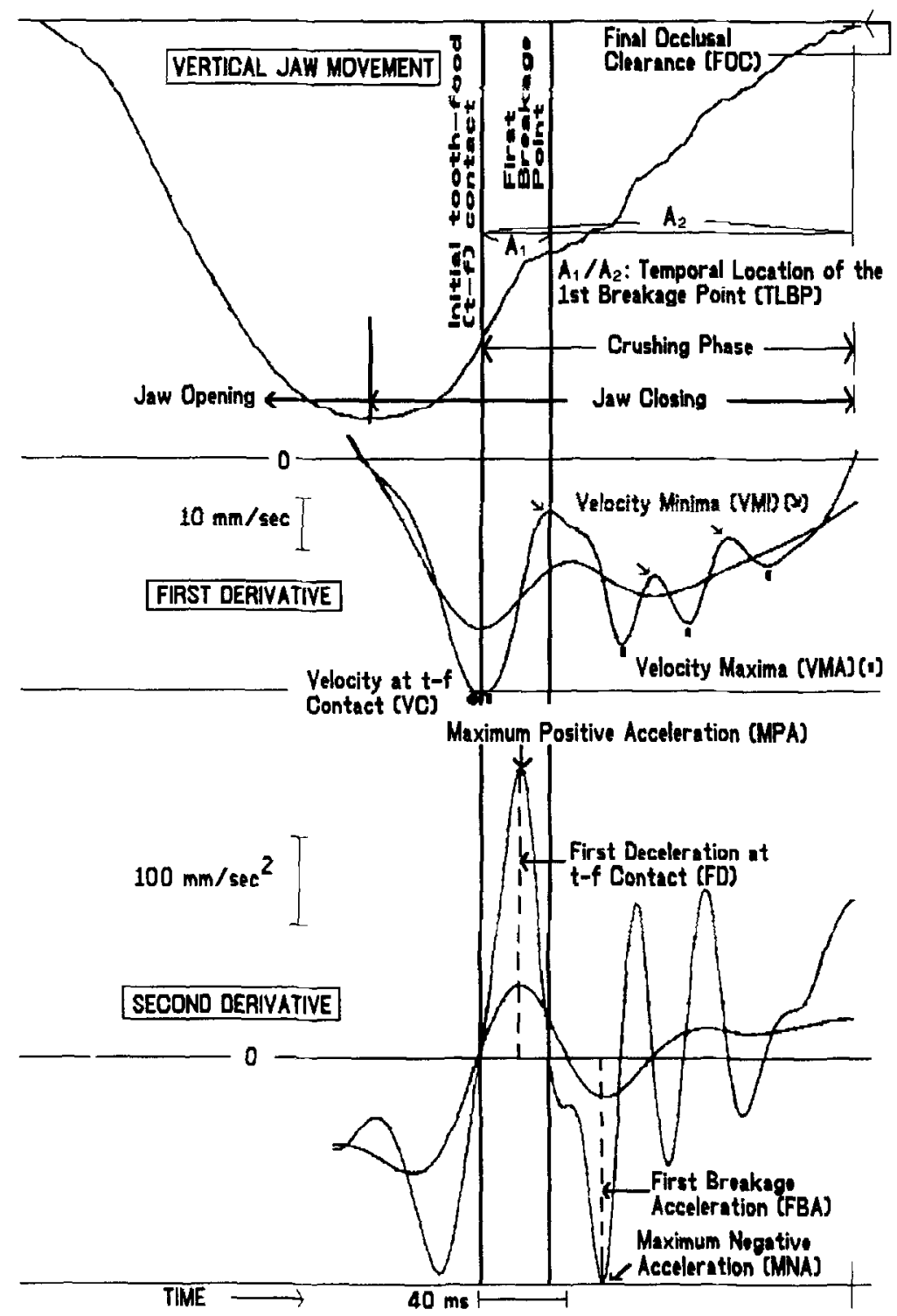

Fig. 1. Diagrammatic representation of jaw movement parameters during crushing; data from the second trial of crushing peanut by subject No. 1 . 


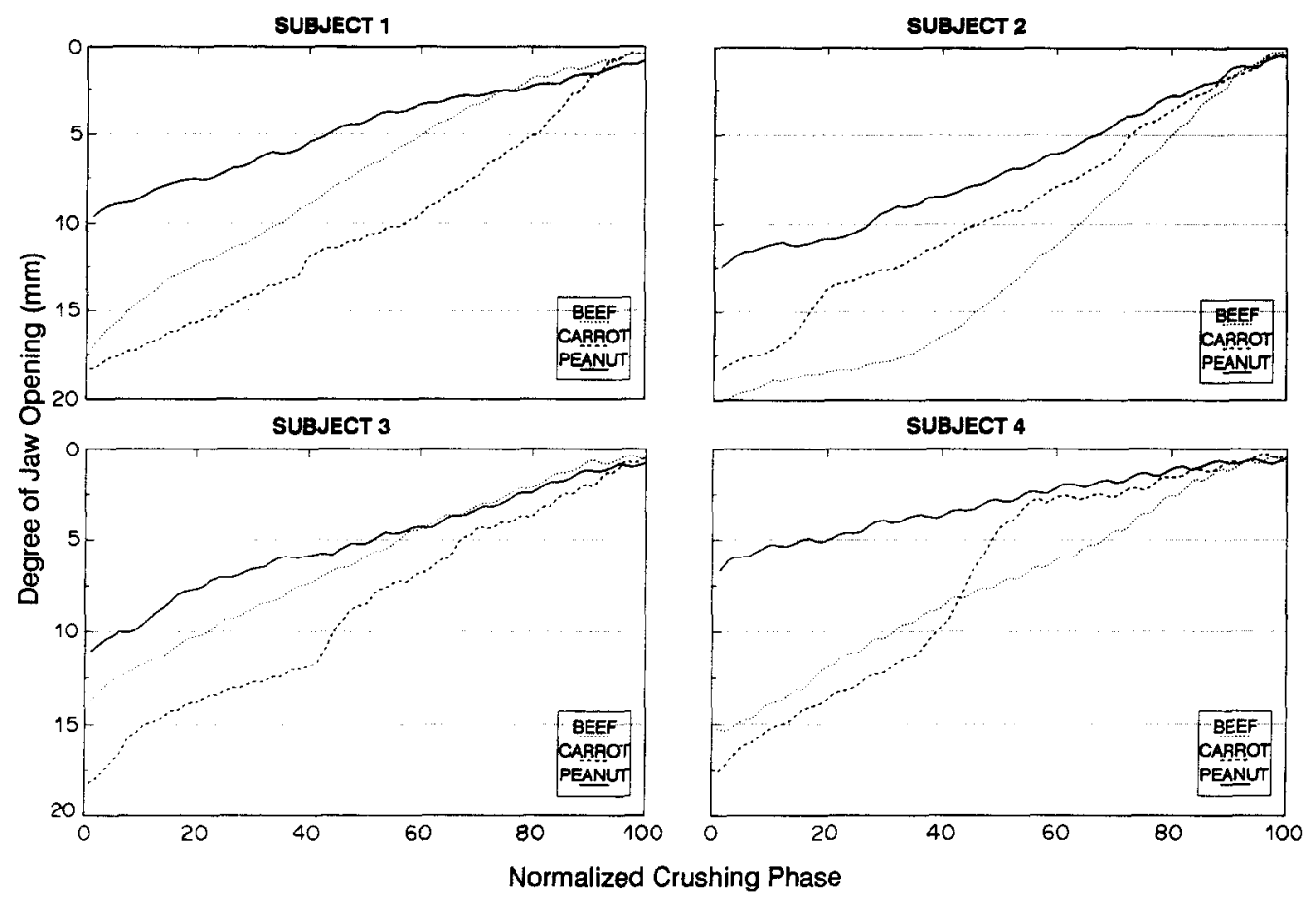

Fig. 2. Vertical component of the incisal point movement during food crushing; data from the first trials of subjects Nos 1-4.

Table 2. Jaw movement dynamics of various testfoods $(95 \%$ confidence interval)

\begin{tabular}{lccc}
\hline $\begin{array}{l}\text { Parameters of jaw } \\
\text { movement dynamics }\end{array}$ & Carrot & Peanut & Beef \\
\hline VMI (unit/cycle) & $2.70 \pm 0.66$ & $2.90 \pm 0.54$ & $0.90 \pm 0.20$ \\
VMA (unit/cycle) & $2.60 \pm 0.60$ & $2.90 \pm 0.68$ & $1.70 \pm 0.30$ \\
MPA $\left(10^{2} \mathrm{~mm} / \mathrm{s}^{2}\right)$ & $2.98 \pm 1.08$ & $1.43 \pm 0.53$ & $0.75 \pm 0.26$ \\
MNA $\left(10^{2} \mathrm{~mm} / \mathrm{s}^{2}\right)$ & $3.46 \pm 1.00$ & $2.65 \pm 0.57$ & $2.14 \pm 0.61$ \\
FBA $\left(10^{2} \mathrm{~mm} / \mathrm{s}^{2}\right)$ & $2.19 \pm 1.09$ & $1.25 \pm 0.53$ & $0.75 \pm 0.26$ \\
FOC $(1 / 10 \mathrm{~mm})$ & $1.00 \pm 0.58$ & $3.35 \pm 1.30$ & $1.50 \pm 1.06$ \\
FD $\left(10^{2} \mathrm{~mm} / \mathrm{s}^{2}\right)$ & $2.32 \pm 0.83$ & $2.54 \pm 0.68$ & $1.78 \pm 0.60$ \\
VC $(\mathrm{mm} / \mathrm{s})$ & $44.44 \pm 10.65$ & $34.00 \pm 3.87$ & $34.49 \pm 6.58$ \\
TLBP $(\%)$ & $25.90 \pm 7.99$ & $17.45 \pm 5.70$ & $33.17 \pm 11.47$ \\
\hline
\end{tabular}

Table 3. Multiple comparisons

\begin{tabular}{llccc}
\hline $\begin{array}{l}\text { Parameters of } \\
\text { jaw dynamics }\end{array}$ & ANOVA & $\begin{array}{c}\text { Carrot versus } \\
\text { peanut }\end{array}$ & $\begin{array}{c}\text { Carrot versus } \\
\text { beef }\end{array}$ & $\begin{array}{c}\text { Peanut versus } \\
\text { beef }\end{array}$ \\
\hline $\begin{array}{l}\text { Count of velocity } \\
\text { minima (VMI) }\end{array}$ & $0.0006^{* * *}$ & 0.265 & $0.010^{* *}$ & $0.012^{*}$ \\
$\begin{array}{l}\text { Count of velocity } \\
\text { maxima (VMA) }\end{array}$ & $0.0297^{*}$ & 0.794 & 0.131 & $0.038^{*}$ \\
$\begin{array}{l}\text { Maximum positive } \\
\text { acceleration (MPA) }\end{array}$ & $0.0251^{*}$ & 0.251 & $0.037^{*}$ & 0.130 \\
$\begin{array}{l}\text { Maximum negative } \\
\text { acceleration (MNA) }\end{array}$ & 0.0537 & - & - & - \\
$\begin{array}{l}\text { First breakage } \\
\text { acceleration (FBA) }\end{array}$ & 0.1229 & - & - & - \\
$\begin{array}{l}\text { Final occlusal } \\
\text { clearance (FOC) } \\
\text { First deceleration } \\
\text { at tooth-food contact (FD) }\end{array}$ & $0.0162^{*}$ & $0.046^{*}$ & 0.787 & $0.035^{*}$ \\
$\begin{array}{l}\text { Velocity at } \\
\text { tooth-food contact (VC) }\end{array}$ & 0.1161 & 0.822 & 0.072 & 0.119 \\
$\begin{array}{l}\text { Temporal location } \\
\text { of Ist BP (TLBP) }\end{array}$ & 0.1830 & - & - & - \\
\hline
\end{tabular}

***p $p<0.001 ; * * 0.001<p \leqslant 0.01 ; * 0.01<p<0.05$. 


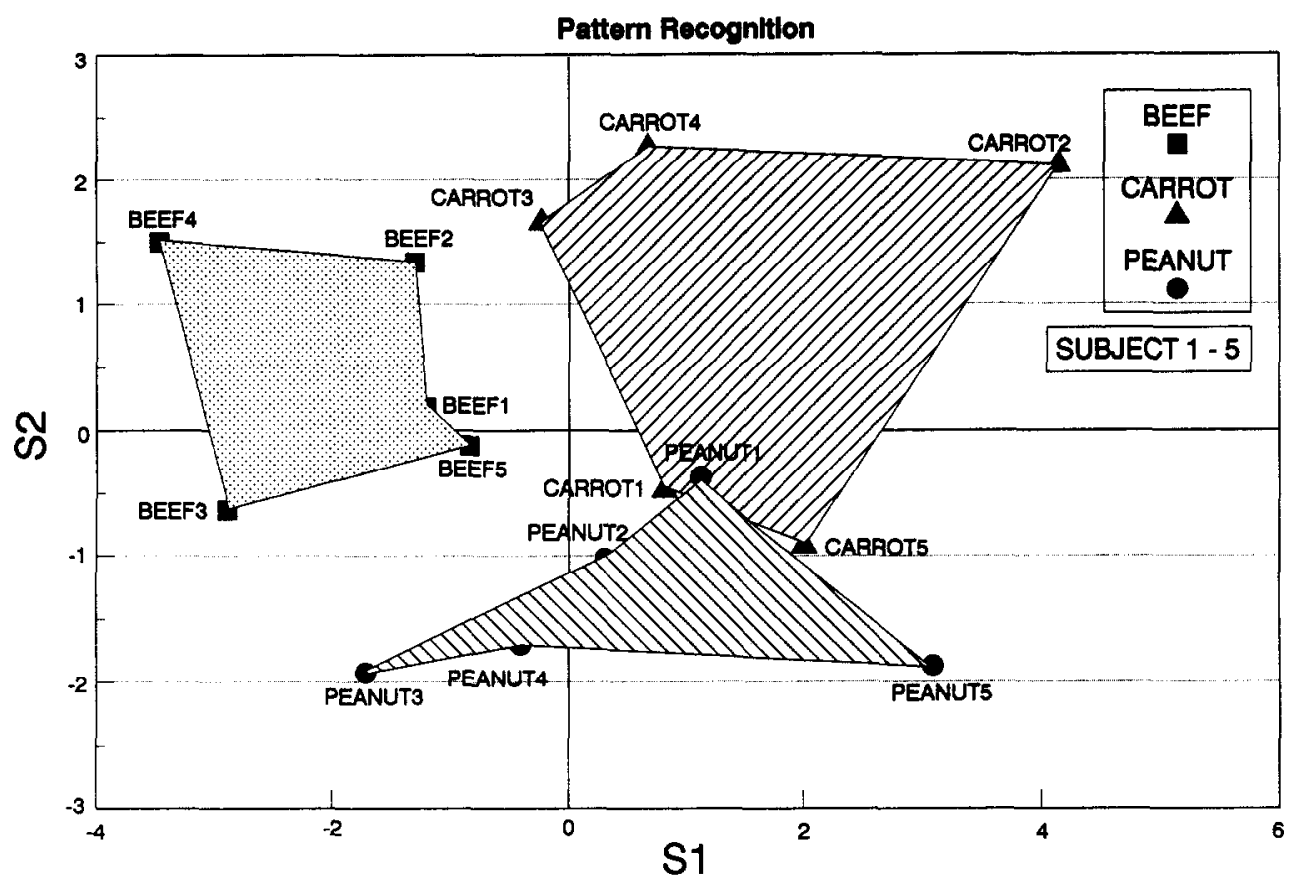

Fig. 3. Summary of the principal component analysis of vertical jaw movement dynamics during food crushing. S1 and S2 are the principal component scores of autoscaled data. Areas indicate the range within which the observations for each food occurred. Note the absence of overlap between beef and both carrots or peanuts.

movement trace was due to the inherent food properties (Fig. 4).

\section{DISCUSSION}

We earlier showed that different test foods have particular in vitro breakage characteristics (Wang and Stohler, 1990). This is significant, because it has been shown that the chewing behaviour is influenced by the nature of the test-food (Ahlgren, 1966; Moller, 1966; Luschei and Goodwin, 1974; Bates, Stafford and Harrison, 1975; Hiiemae, 1978; Haraldson and Ingervall, 1979; Hylander and Johnson, 1989).

We now wanted to establish the extent to which the force-time breakage characteristics of various foods in vitro would affect actual mandibular movement during crushing. This influence, assessed by crosscorrelation analysis of jaw movements and in vitro

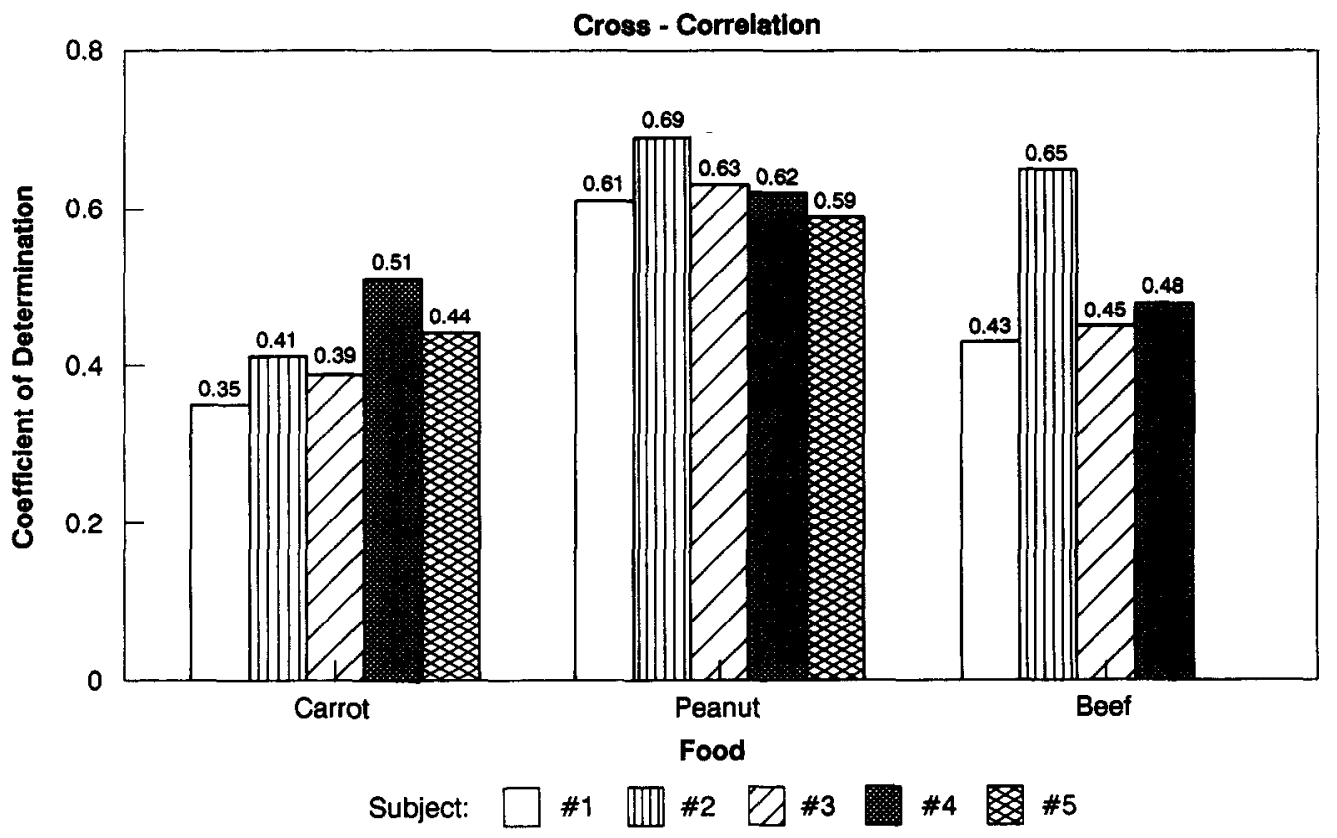

Fig. 4. Results of cross-correlation analysis of the vertical incisal point movement and the in vitro force-time characteristics of foods. 
breakage characteristics, was less pronounced for carrot and beef than for peanut. In our 5 subjects, between 59 and $69 \%$ of the variability of the jaw movement during peanut crushing could be explained on the basis of the in vitro breakage characteristics. Overall, the in vitro characteristics explained about half of the variation observed in the vertical jaw movement trace.

Both pattern recognition routines, based upon principal component analysis and multiple comparison procedures of analysis of variance, were applied to assess the degree to which the food could be identified from observations of jaw movement dynamics during crushing. The results of these two analytical schemes were in agreement. Beef could be distinguished from carrot and peanut with greater certainty than peanut from carrot. When comparing in vitro force-time curves (Wang and Stohler, 1990) with the corresponding jaw movement traces, it is apparent that the masticatory system acts as a lowpass filter, smoothing the high-frequency components of the in vitro breakage characteristics. It is therefore not surprising that the identifiability of foods with distinctly different high-frequency components is reduced because the high-frequency breakage characteristics were attenuated. This is believed to account for the fact that the distinction between carrot and peanut was not as clear as expected.

Based on these observations, we concluded that the inherent, low-pass, filter properties of the masticatory apparatus limit the range of sensory and motor function of the jaw. This has an impact on force control and could account for the fact that the difference between the forces at which motor neurones are recruited during slow ramp and ballistic contractions is small in the case of the masseter as compared to limb systems (Desmedt and Godaux, 1978). By limiting the functional range of the masticatory apparatus through low-pass filtering, finer details in the in vitro force-time breakage properties of food are eliminated, which would otherwise necessitate sensory feedback. We believe that the observed phenomenon favours the production of the appropriate motor output with minimal peripheral feedback.

Acknowledgements-We wish to thank Dr Charles J. Kowalski, Statistical Research Unit, School of Dentistry,
University of Michigan for his helpful suggestions. This study was supported by NIH-NIDR R01 DE08606.

\section{REFERENCES}

Ahlgren J. (1966) Mechanism of mastication. Acta odont. scand. 24 (Suppl. 44), 1-109.

Bates J. F., Stafford G. D. and Harrison A. (1975) Masticatory function-a review of the literature (II). Speed of movement of the mandible, rate of chewing and forces developed. J oral Rehab. 2, 340-369.

Desmedt J. E. and Godaux E. (1978) Ballistic contractions in fast or slow human muscles: discharge patterns of single motor units. J. Physiol. (Lond.) 285, 185-196.

Enomoto S., Schwartz G., Lund J. P. and Nakamura Y. (1987) The effect of cortical ablations on mastication in the rabbit. J. dent. Res. 66 (Abstr. 1985).

Haraldson T. and Ingervall B. (1979) Muscle function during chewing and swallowing in patients with osteointegrated oral implant bridges. An electromyographic study. Acta odont. scand. 37, 207-216.

Hiiemae K. M. (1978) Mammalian mastication: a review of the activity of the jaw muscles and the movements they produce in chewing. In: Development, Function, and Evolution of Teeth (Edited by Butler B. M. and Joysey K. A.) pp. 359-398. Academic Press, London.

Hoffman D. S. and Luschei E. S. (1980) Responses of monkey precentral cortical cells during a controlled biting task. J. Neurophysiol. 44, 333-348.

Hylander W. L. and Johnson K. R. (1989) The relationship hetween masseter force and masseter electromyogram during mastication in the monkey Macaca fascicularis. Archs oral Biol. 34, 713-722.

Luschei E. S. and Goodwin G. M. (1974) Patterns of mandibular movement and jaw muscle activity during mastication in monkey. J. Neurophysiol. 37, 954-966.

Luschei E. S. and Goodwin G. M. (1975) Role of monkey precentral cortex in control of voluntary jaw movements. J. Neurophysiol. 38, 146-157.

Luschei E. S. and Goldberg L. J. (1981) Neural mechanisms of mandibular control: mastication and voluntary biting. In: Handbook of Physiology, Vol II: Motor Control (Edited by Brooks V. B.) pp. 1237-1274). American Physiological Society. Washington.

Moller E. (1966) The chewing apparatus. Acta Physiol. Scand. 69 (Suppl. 280), 1-228.

Stohler C. S., Ashton-Miller J. A. and Carlson D. S. (1988) The effects of pain from the mandibular joint and muscles on masticatory motor behavior in Man. Archs oral Biol. 33, $175-182$.

Wang J.-S. and Stohler C. S. (1990). Textural properties of food used in study of mastication. J. dent. Res. 69, $1546-1550$. 